\title{
APICAL CLEANLINESS AFTER REMOVAL OF TOTALFILL BIOCERAMIC SEALER VERSUS AH-PLUS EPOXY-RESIN SEALER
}

\author{
Mohammed Hamdi Atteia*
}

\begin{abstract}
Objectives: The aim of the present study was to evaluate the apical cleanliness following canal enlargement after removal of canal obturating material containing TotalFill bioceramic Sealer as compared to AH-Plus epoxy-resin sealer.

Materials \& Methods: 40 obturated single-canal roots were divided into 2 groups; AH-Plus (Gp-I) and TotalFill (Gp-II) 15 specimen each. 5 specimens were kept as control for each group. Canal filling was removed and canals were enlarged. According to the file size used for canal enlargement, each group was divided into 3 sub-groups; A, B, and C (\#30-0.04\%, \#35-0.04, and $\# 35-0.04 \%$, respectively). Roots were split and the apical third was examined under SEM. Digital image analysis was done for the photomicrographs.

Results: SEM images of the control groups revealed more condensed and widely spread particles of TotalFill in comparison to AH-Plus. In AH-Plus subgroups: The recorded means (in a descending order) of remnants for subgroups I_A, I_B, and I_C were 27.3, 24.23, and 0.94, respectively. There was a significant statistical difference $(\mathrm{P} \leq 0.05)$ between the test subgroups, except for subgroups I_A/I_B where the difference was statistically insignificant $(\mathrm{P}>0.05)$. In TotalFill subgroups: The recorded means (in a descending order) of remnants for subgroups II_A, II_B, and II_C were 48.16, 39.3, and 30.42, respectively. There was a statistically insignificant difference $(\mathrm{P}>0.05)$ between the test subgroups, except for subgroups II_A/II_C, where the difference was statistically significant $(\mathrm{P} \leq 0.05)$. In file \#40 sub-groups: There was a statistically significant difference $(\mathrm{P} \leq 0.01)$ between the recorded amount of remnants between AH-Plus and TotalFill subgroups. TotalFill recorded higher amount of remnants.

Conclusions: Within the parameters of this study - after canal desobturation -, increasing the size of the apical preparation - within limits - improves the cleanliness of canal walls at the apical third area. TotalFill sealer leaves more remnants on the dentin surface of the apical third when compared to AH-Plus sealer. It's better to enlarge the apical third of the canal two or three sizes larger than the master apical file (in case of desobturation of bioceramic-sealer-containing canal filling) to ensure better cleanliness of the area.
\end{abstract}

KEYWORDS: Apical preparation, apical cleaning, bioceramic sealer, epoxy resin sealer, TotalFill, AH-Plus, retreatment.

* Associate Professor of Endodontics, Department of Endodontics, Faculty of Oral and Dental Medicine, Cairo University, Egypt. 


\section{INTRODUCTION}

Intra-canal pathogens are the primary cause of post-treatment failure. These microbes can hide and survive in canal irregularities and dentinal tubules. They become persistent and resist removal methods. Elimination of these hidden bacteria is the utmost goal of retreatment maneuvers. The use of gutta-percha as a semi-solid core filling requires a more flowable interface (sealer) that can provide a bi-functinal job; adhesion and hermetic seal to gutta percha surface and canal wall irregularities ${ }^{[1]}$.

Proper removal of root canal filling material - after failure - allows for proper contact of irrigants and intracanal medicaments to the root canal walls. Not only the preparation size and type of the sealer that can affect the outcome of retreatment procedures ${ }^{[2]}$, but also do the same other factors like; solvent-type, duration of solvent action, retrieving instrument design, and irrigant-type and technique.

Different types of sealers are available in the market. Bioceramic sealers are among the most famous nowadays. Albeit it has been available for use in endodontics for the last three decades, bioceramics uprise is mostly related to the recent advances in nanotechnology manufacturing. These ceramic materials are specially fabricated for medical and dental use with minimal or zero tissue reaction, hence the name "Bio-". They contain alumina, zirconia, bioactive glass, glass ceramics, hydroxyapatite, and calcium phosphates ${ }^{[3]}$. Glass and calcium phosphate are bioactive ingredients which stimulate the growth of healthy surrounding tissues, while zirconia and alumina are the bioinert ingredients which stimulate negligible or no biological tissue reaction ${ }^{[4,5]}$. Biocermics also can be degradable or non-degradable. According to their stability, they have various clinical applications. Most commonly they can be used as orthopedic cements, bone graft substitutes, or as a biocompatible coating for metallic implants ${ }^{[6]}$.
TotalFill is a recently introduced pre-mixed bioceramic sealer with numerous merits. Perfect flow, minimum setting time, dimensional stability during setting (rather, it slightly expands), hydrophilicity, biocompatibility, bioactivity and antibacterial effect, all are among its proclaimed advantages. It can bond to both dentin and TotalFill $\mathrm{BC}$ gutta percha points. However, it can be used with regular gutta percha points as well. It's available as pre-loaded $1.5 \mathrm{~g}$ syringe ${ }^{[7]}$. Forming a stronger bond to dentin as compared to other root canal sealers ${ }^{[8]}$, it can improve the fracture resistance of the root after treatment ${ }^{[9]}$.

Retreatability of bioceramic sealers is amongst the ideal requirements of any root canal sealer that ensures and affects the periapical health and healing ${ }^{[10]}$. Therefore, the aim of this study was to evaluate and compare the apical cleanliness of dentin following canal enlargement after removal of TotalFill sealer versus AH-Plus sealer using scanning electron microscope (SEM) and digital image analysis. No difference in the apical cleanliness after removal of either sealers was taken as a null hypothesis.

\section{MATERIALS AND METHODS}

A sum of 40 single-canal human teeth with straight roots were used. Teeth were immersed in $0.5 \%$ solution of chloramine-T (Merck, Darmstadt, Germany) for 2 days for disinfection and then stored in $4^{\circ} \mathrm{C}$ distilled water. All teeth were decapitated at the level of cement-enamel junction. Canals were cleaned and shaped up to SU Revo-S (\#25-0.06) niti rotary file (MICRO-MEGA, Besancon Cedex, France).

$3 \%$ solution of sodium hypochlorite was used as an irrigant. After canal dryness, all canals were obturated using single-cone matched gutta percha and either of AH-Plus (DENTSPLY DeTrey GmbH, Lnstanz, Germany) (group-I: 20 canal) or TotalFill BC sealer (Brasseler Savannah, GA 31419, USA) 
(group-II 20 canal). All roots were incubated at $37^{\circ} \mathrm{C}$ for one week in humid conditions. Five specimens were kept as control for each group (Control-I and Control-II). The fifteen canals of each group had their filling removed using gates glidden burs size \#3 (Dentsply, Maillefer, Swiss-made), d-Lemoninebased solvent (Carvene, Prevest DentPro Limited, India), and R-Endo kit (MICRO-MEGA, Besancon Cedex, France). The dissolved canal filling was brought into an emulsion which was adsorbed continuously using paper points.

Based on file size used for canal enlargement, each group was further divided into 3 sub-groups; A, B, and C (Revo-S \#30-0.04\%, \#35-0.04, and \#35$0.04 \%$, respectively). Empty canals were protected by fitting-in greater taper paper points (Autofit, Sybron Endo, CA, USA), and all roots (including those of the control groups) were split longitudinally using double sided metal disc, cement spatula and miniature mallet. Canal fillings of the split halves of control groups, were pulled away (using the tip of a Stieglitz forceps holding the coronal end of the gutta percha) to leave the split halves empty.

The Apical third region of all specimens was examined under the environmental scanning electron microscope (ESEM) (Quanta 250 FEG, FEI Co., Netherlands) - present in The Central Laboratories of The Egyptian Mineral Resources Authority - Ministry of Petroleum - at two magnification powers; $200 \mathrm{X}$ and 1000X. Images of 200X magnification were processed and analyzed digitally using (Image J 1.51n software, Wayne Rasband National Institute of Health, USA) to calculate the percentage of remaining surface debris in relation to the total canal space of the apical third region. Images of $1000 \mathrm{X}$ magnification were evaluated and described. Results were tabulated and statistically analyzed using Mann-Whitney test for unpaired data and Steel Dewas test for pairwise comparisons of one-way layout design. The remnants index (RI) was calculated as per the formula: RI (Remnant Index $)=[($ subgroup reading $/$ Control reading) x100]. Statistical significance was considered at $\mathrm{P}<0.05$.

\section{RESULTS}

Scanning electron microscope (SEM) photomicrographs of the control groups showed deposition of sealer particles over canal walls. The deposits were heavier and more condensed in TotalFill (Control_2) than in AH-Plus (control_1). AH-Plus samples revealed few spheroidal-like filler particles dispersed in a transparent matrix-like structure, fig-4. On the other hand, heavily condensed spindle-like particles of TotalFill samples were nearly masking dentin surface structure, fig-5.

SEM photomicrographs of the AH-Plus subgroups (figs 6-8) revealed smeared dentinal walls with remnants of canal filling that varied between moderate in subgroups I_A and I_B (figs- 6,7) to scarce in subgroup I_C (Fig-8). SEM photomicrographs of the TotalFill subgroups (figs 9-11) revealed smeared dentinal walls with remnants of canal filling that varied between heavy in subgroups II_A and II_B (figs- 6,7) to moderate in subgroup II_C (fig-8).

The amount of remnants in the apical third is decreasing as the size of the apical preparation increases. Subgroups (A) have the highest remnants records followed by subgroups (B) and (C). Subgroups (C) had the lowest remnants records, table 2 and figs- 1-3. In AH-Plus subgroups: There was a significant statistical difference $(\mathrm{P} \leq 0.05)$ between the test subgroups, except for subgroups I_A/I_B where the difference was statistically insignificant $(\mathrm{P}>0.05)$. The means of readings of surface remnants in subgroups I_A, I_B, and I_C were 27.3, 24.23 , and 0.94 , respectively, and in a descending order, table 2, figs- 1, 2. In TotalFill subgroups: there was a statistically insignificant difference $(\mathrm{P}>0.05)$ between the test subgroups, except for subgroups II_A/II_C, where the difference was statistically 
significant $(\mathrm{P} \leq 0.05)$. The means of readings of surface remnants in subgroups II_A, II_B, and II_C were $48.16,39.3$, and 30.42 , respectively, and in a descending order, table 2, figs- 1,3 .

In file \#30 sub-groups: There was a statistically significant difference $(\mathrm{P} \leq 0.01)$ between the recorded amount of remnants between AH-Plus and TotalFill subgroups. TotalFill recorded a higher amount of surface remnants, table 1, figs-1, 6, 9. In file \#35 sub-groups: although TotalFill recorded higher amount of surface remnants, there was a statistically insignificant difference $(\mathrm{P}>0.05)$ between the recorded amount of remnants between AH-Plus and TotalFill subgroups, table1, fig-1, 7, 10. In file \#40 sub-groups: there was a statistically significant difference $(\mathrm{P} \leq 0.01)$ between the recorded amount of surface remnants of AH-Plus versus TotalFill subgroups. TotalFill recorded higher amount of surface remnants, table 1 , figs- $1,8,11$.

In AH-Plus subgroups: the lowest remnant index was recorded for file \#40 (sub-group I_C) followed by file \#35 (I_B), and file \#30 (I_A) in an ascending order, table 3 , and fig-1. In TotalFill subgroups: the lowest remnant index was recorded for file \#40 (sub-group II_C) followed by file \#35 (II_B), and file \#30 (II_A) in an ascending order, table 3, and fig-1.

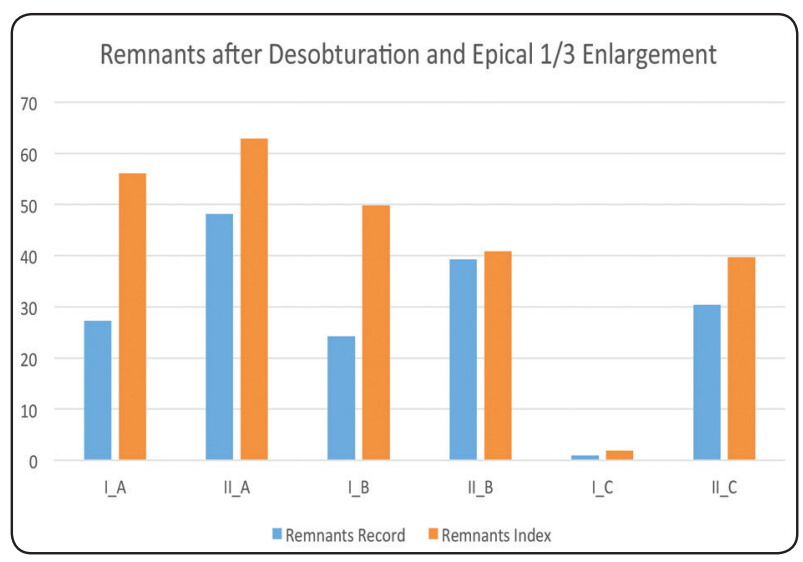

Fig. (1) Radiographic signs of good apical and periradicular healing when combined with clinically asymptomatic tooth denote successful root canal treatment.

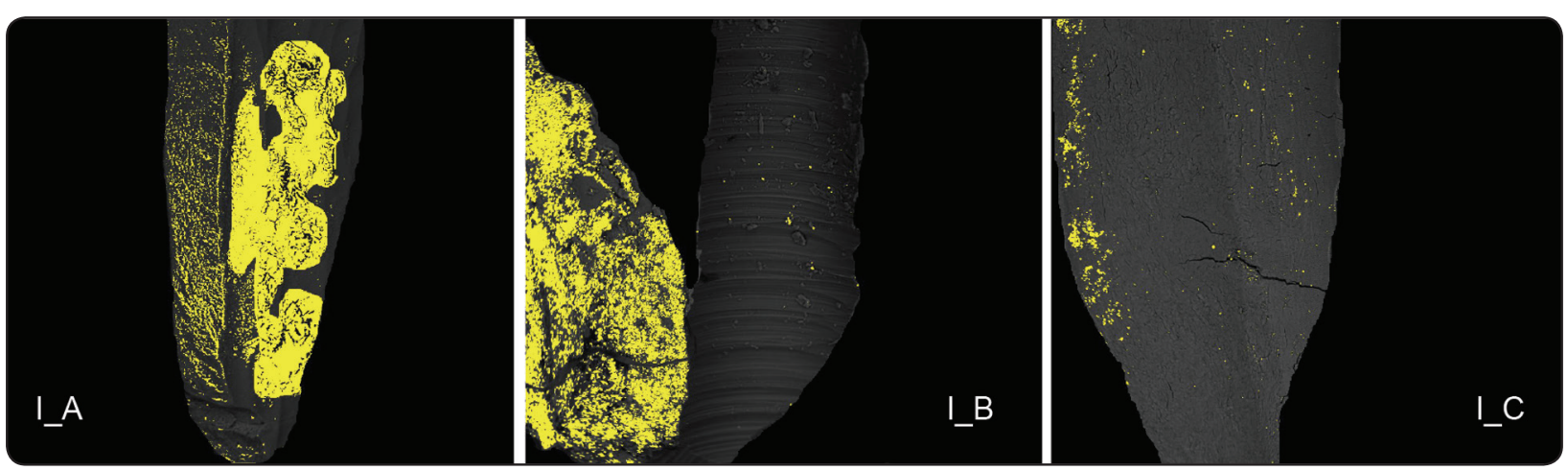

Fig. (2) Digital Image Analysis of the apical third of AH-Plus subgroups.
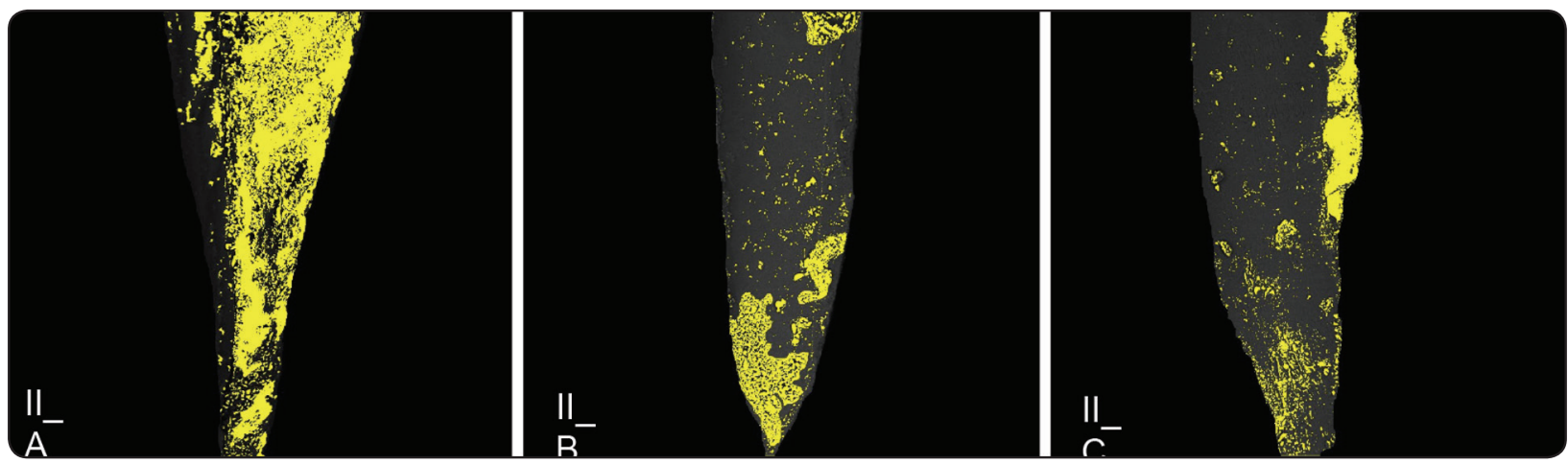

Fig. (3) Digital Image Analysis of the apical third of The TotalFill subgroup. 

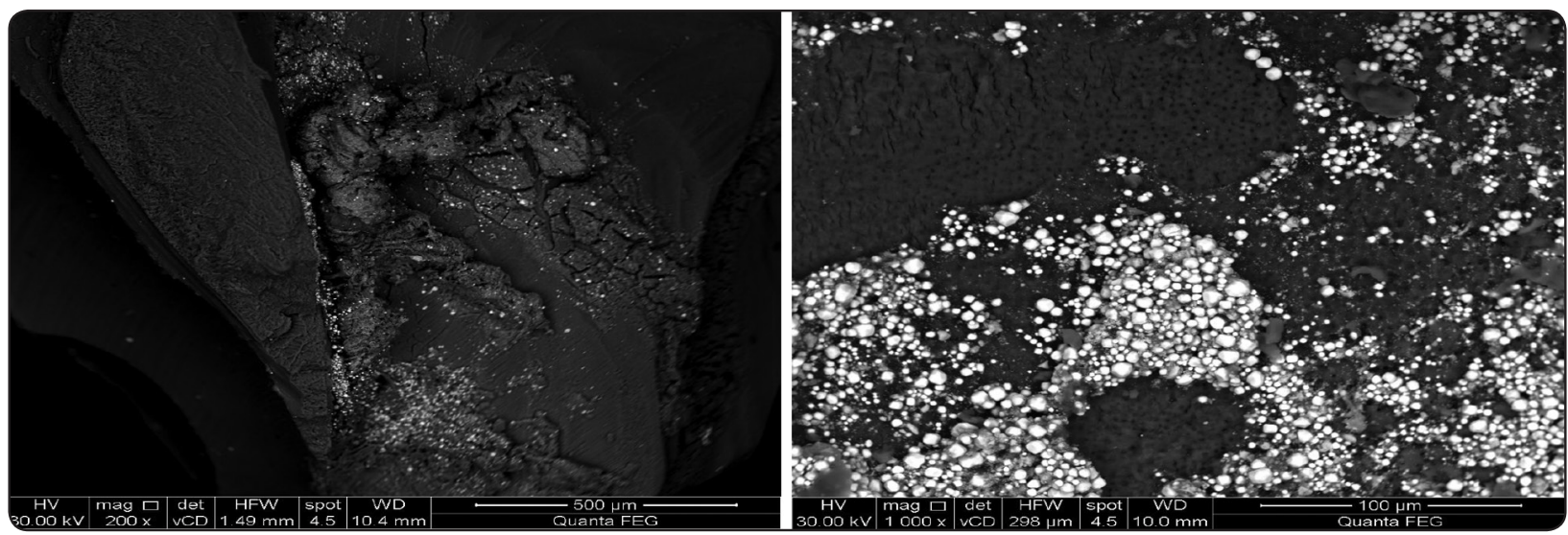

Fig. (4) SEM photomicrograph of unremoved sealer particle in the apical third of AH-Plus control group (200X left, 1000X right).

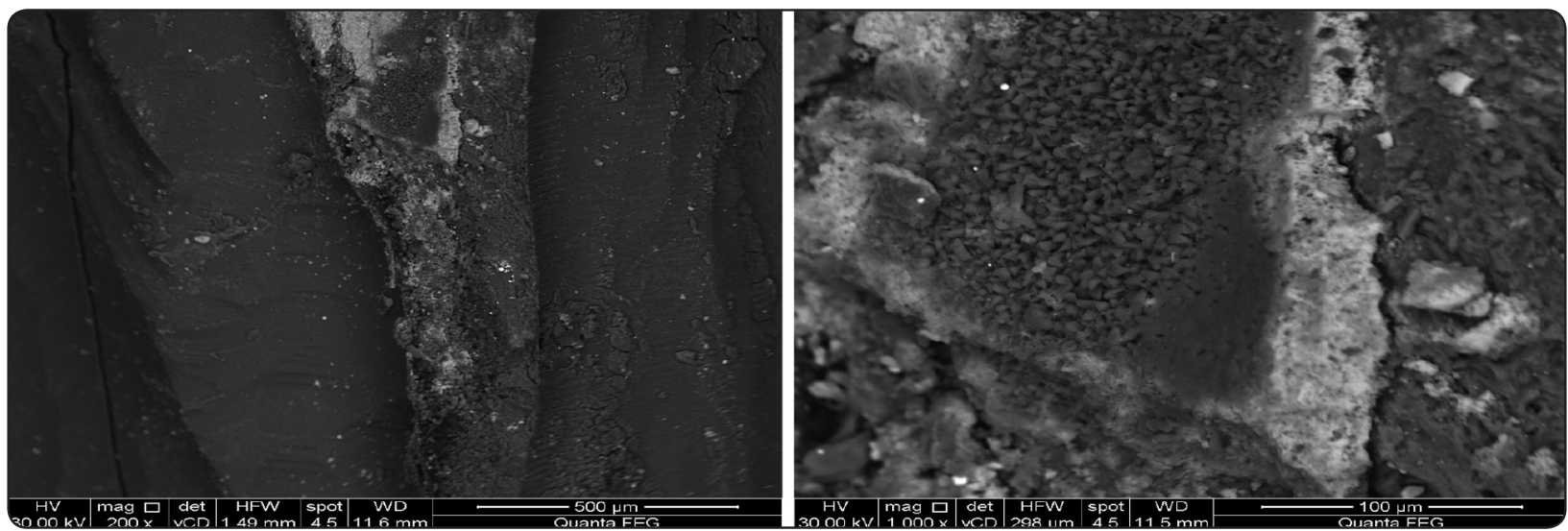

Fig. (5) SEM photomicrograph of unremoved sealer particle in the apical third of TotalFill control group (200X left, 1000X right)

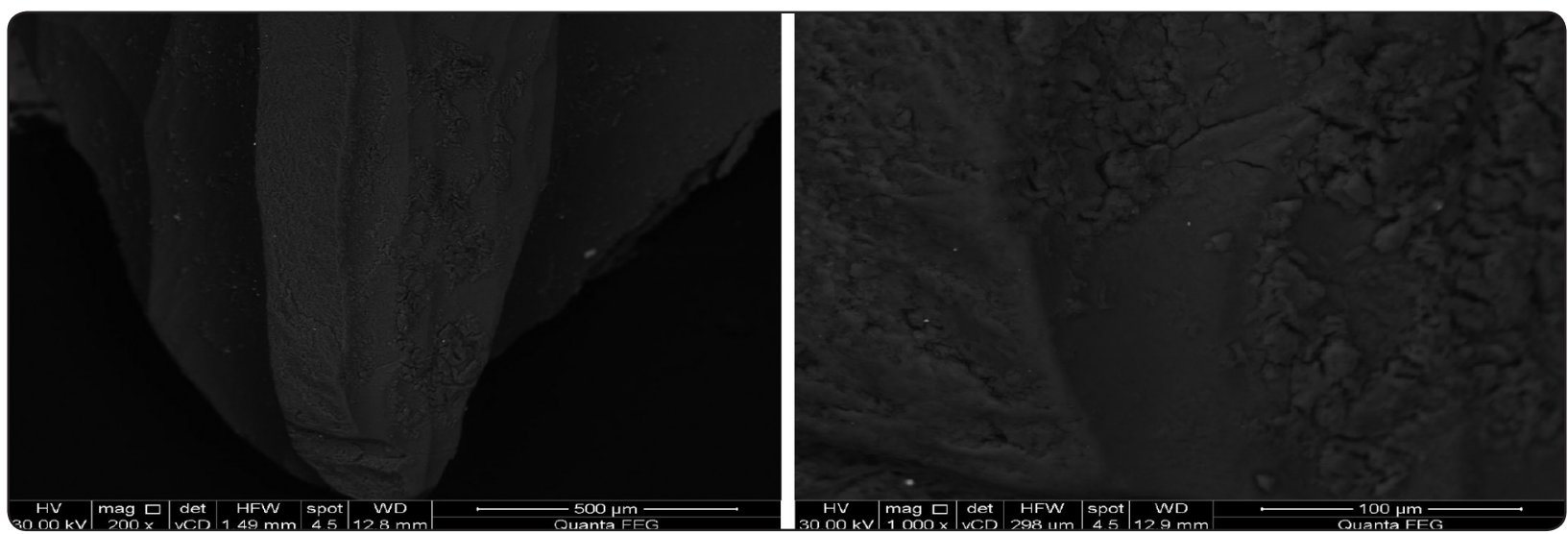

Fig. (6) SEM photomicrograph of the enlarged apical third (up to size \#30-0.04) of the AH-Plus subgroup I_A (200X left, 1000X right). 


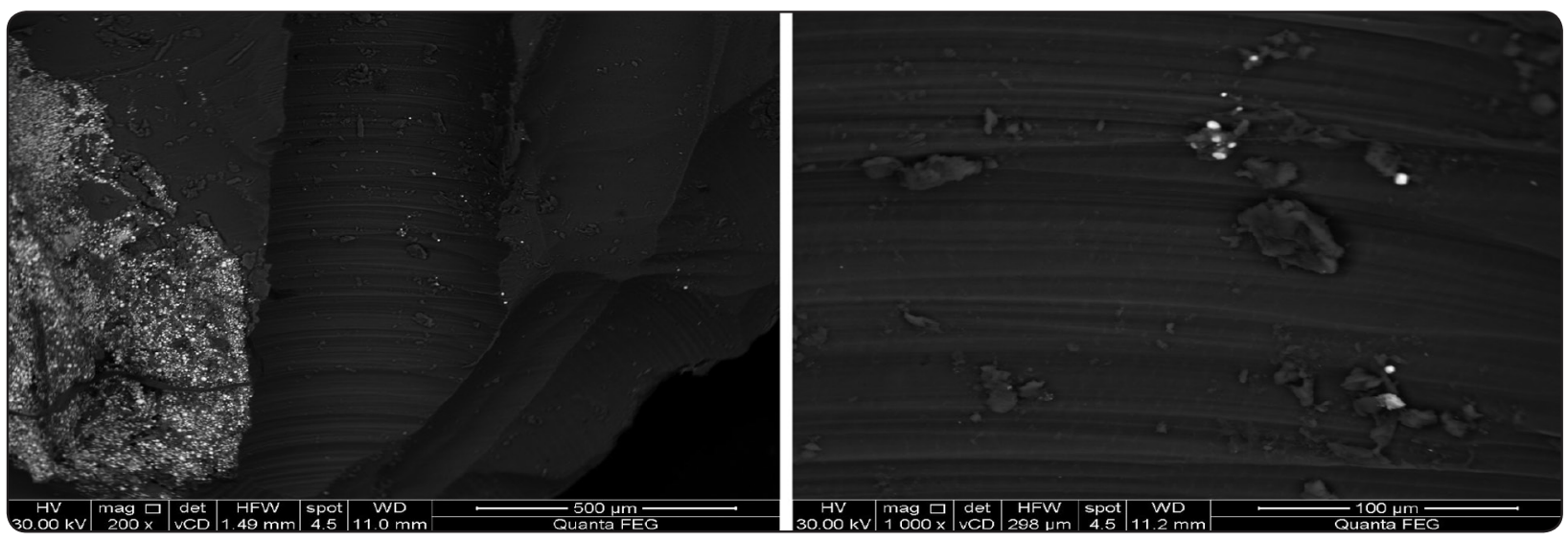

Fig. (7) SEM photomicrograph of the enlarged apical third (up to size \#35-0.04) of the AH-Plus subgroup I_B (200X left, 1000X right).

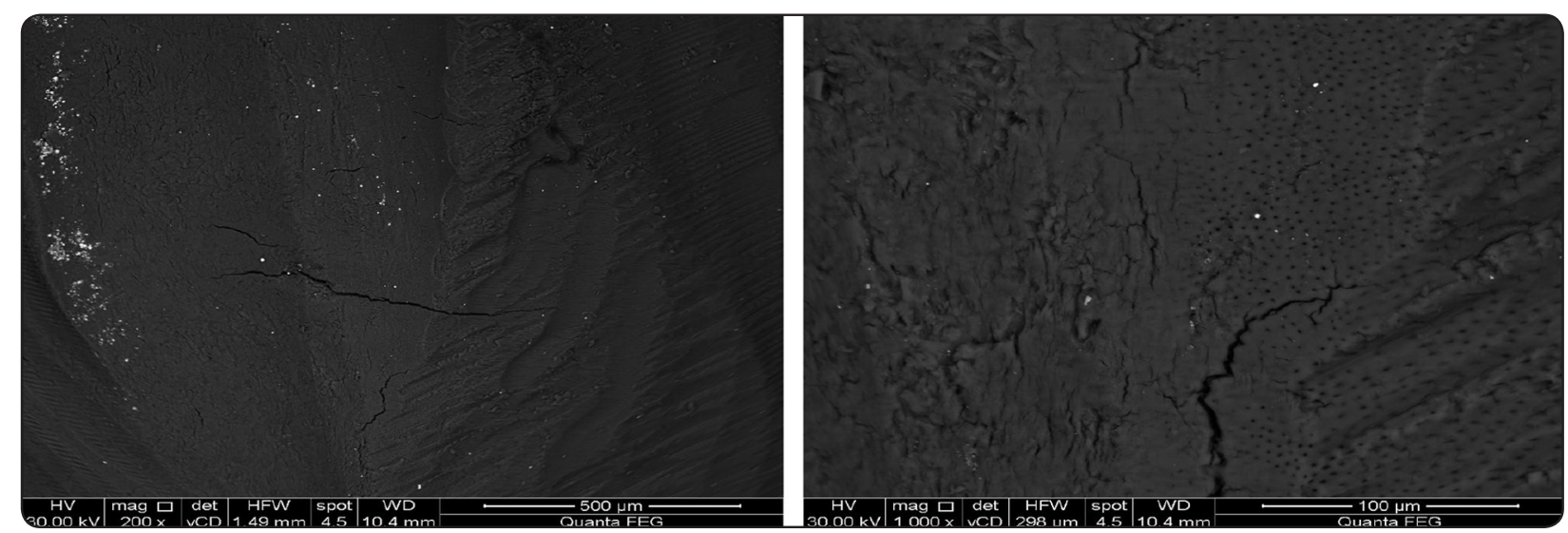

Fig. (8) SEM photomicrograph of the enlarged apical third (up to size \#40-0.04) of the AH-Plus subgroup I_C (200X left, 1000X right).

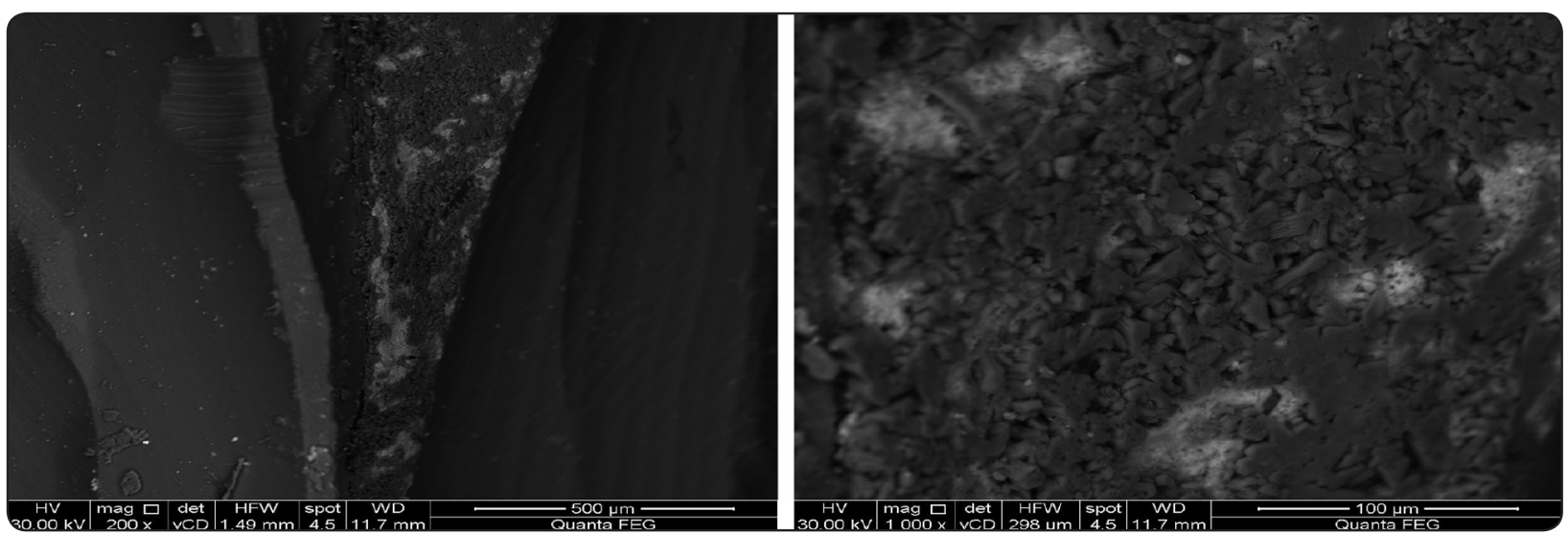

Fig. (9) SEM photomicrograph of the enlarged apical third (up to size \#30-0.04) of the TotalFill subgroup II_A (200X left, 1000X right). 


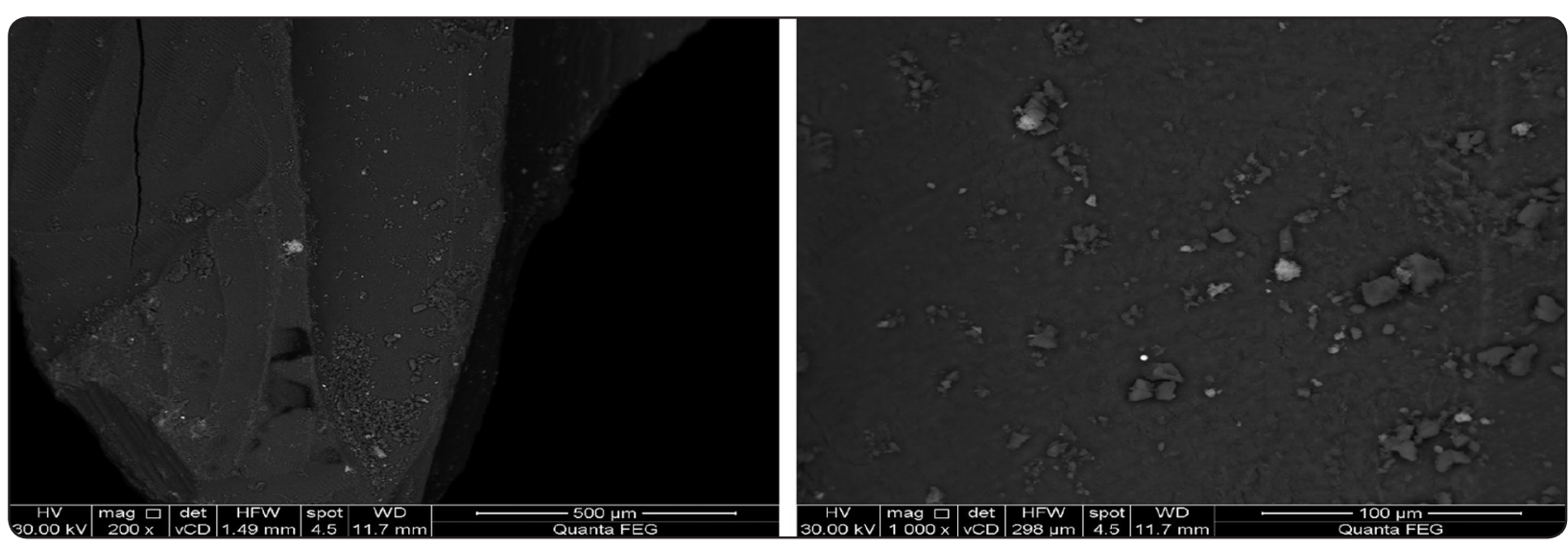

Fig. (10) SEM photomicrograph of the enlarged apical third (up to size \#35-0.04) of the TotalFill subgroup II_B (200X left, 1000X right).

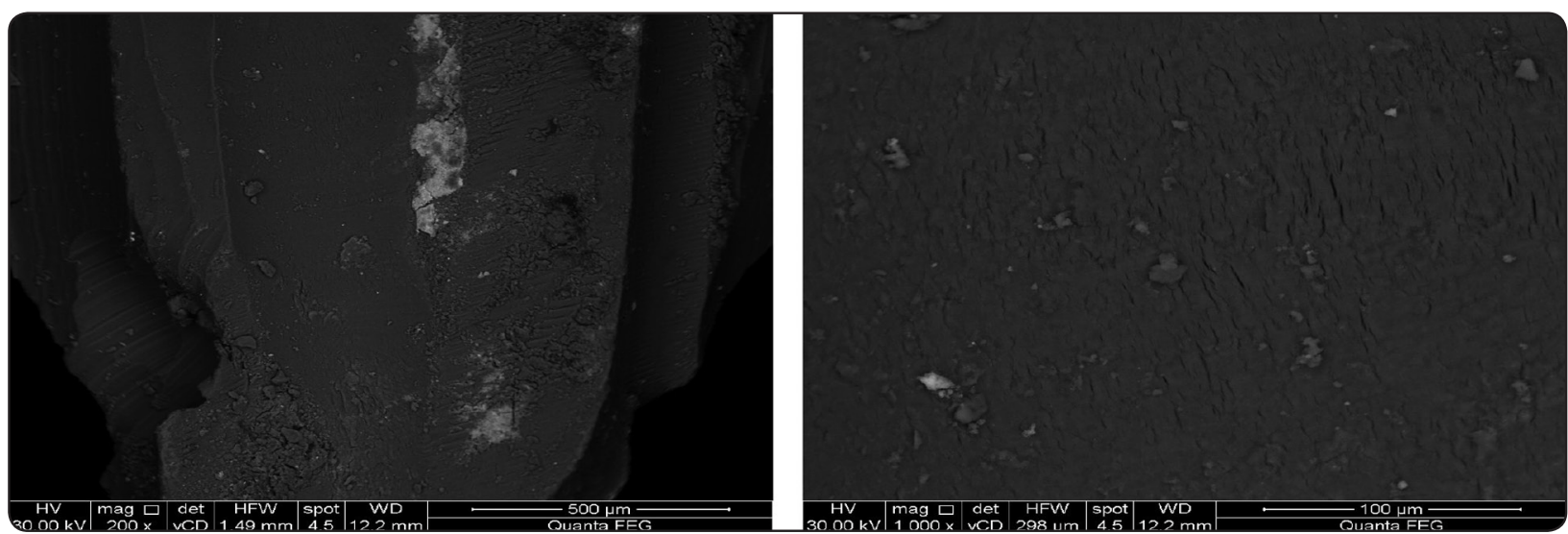

Fig. (11) SEM photomicrograph of the enlarged apical third (up to size \#40-0.04) of the TotalFill subgroup II_C (200X left, 1000X right).

TABLE (1) Wilcoxon (Mann-whitney) for unpaired data of subgroups of different sealer-type and similar apical file size:

\begin{tabular}{|c|c|c|c|c|c|c|c|c|}
\hline \multirow[t]{3}{*}{ Subgp } & I_A & II_A & Subgp & I_B & II_B & Subgp & I_C & II_C \\
\hline & 36.90 & 48.20 & & 26.88 & 62.50 & & 0.98 & 30.50 \\
\hline & 17.70 & 50.98 & & 24.11 & 16.10 & & 1.22 & 30.00 \\
\hline \multirow[t]{3}{*}{ Data } & 30.04 & 45.30 & Data & 29.33 & 40.08 & Data & 1.05 & 29.60 \\
\hline & 26.89 & 49.00 & & 24.00 & 39.90 & & 0.91 & 30.90 \\
\hline & 24.97 & 47.32 & & 16.83 & 37.92 & & 0.54 & 31.10 \\
\hline $\mathbf{N}$ & 5.00 & 5.00 & $\mathbf{N}$ & 5.00 & 5.00 & $\mathbf{N}$ & 5.00 & 5.00 \\
\hline Mean & 27.30 & 48.16 & Mean & 24.23 & 39.30 & Mean & 0.94 & 30.42 \\
\hline Var & 49.36 & 4.39 & Var & 21.96 & 269.84 & Var & 0.06 & 0.39 \\
\hline Median & 26.89 & 48.20 & Median & 24.11 & 39.90 & Median & 0.98 & 30.50 \\
\hline \multicolumn{9}{|c|}{ Wilcoxon (Mann-Whitney) test } \\
\hline$t^{*}$ & \multicolumn{2}{|c|}{$2.6[* *(\mathrm{P}<=0.01)]$} & \multicolumn{3}{|c|}{$1.57[$ N.S. $(\mathrm{P}>0.05)]$} & \multicolumn{3}{|c|}{$2.6[* *(\mathrm{P}<=0.01)]$} \\
\hline
\end{tabular}


TABLE (2) Steel-Dwass test for pairwise comparisons for One-Way Layout Design of subgroups of different apical file size and similar sealer-type:

\begin{tabular}{|c|c|c|c|c|c|c|c|c|c|}
\hline Subgp & I_A & I_B & I_C & Total & Subgp & II_A & II_B & II_C & Total \\
\hline \multirow{5}{*}{ Data } & 36.90 & 26.88 & 0.98 & & \multirow{5}{*}{ Data } & 48.20 & 62.50 & 30.50 & \\
\hline & 17.70 & 24.11 & 1.22 & & & 50.98 & 16.10 & 30.00 & \\
\hline & 30.04 & 29.33 & 1.05 & & & 45.30 & 40.08 & 29.60 & \\
\hline & 26.89 & 24.00 & 0.91 & & & 49.00 & 39.90 & 30.90 & \\
\hline & 24.97 & 16.83 & 0.54 & & & 47.32 & 37.92 & 31.10 & \\
\hline $\mathbf{N}$ & 5.00 & 5.00 & 5.00 & 15.00 & $\mathbf{N}$ & 5.00 & 5.00 & 5.00 & 15.00 \\
\hline Mean & 27.30 & 24.23 & 0.94 & 17.49 & Mean & 48.16 & 39.30 & 30.42 & 39.29 \\
\hline Var & 49.36 & 21.96 & 0.06 & 168.81 & Var & 4.39 & 269.84 & 0.39 & 134.66 \\
\hline \multicolumn{5}{|c|}{ Steel-Dwass Test } & \multicolumn{5}{|c|}{ Steel-Dwass Test } \\
\hline I_A/I_B & \multicolumn{4}{|c|}{$1.15[$ N.S. $(\mathrm{P}>0.05)]$} & II_A/II_B & \multicolumn{4}{|c|}{$1.57[$ N.S. $(\mathrm{P}>0.05)]$} \\
\hline I_A/I_C & \multicolumn{4}{|c|}{$2.61[*(\mathrm{P}<=0.05)]$} & II_A/II_C & \multicolumn{4}{|c|}{$2.61[*(\mathrm{P}<=0.05)]$} \\
\hline I_B/I_C & \multicolumn{4}{|c|}{$2.61[*(\mathrm{P}<=0.05)]$} & II_B/II_C & \multicolumn{4}{|c|}{$1.57[$ N.S. $(\mathrm{P}>0.05)]$} \\
\hline
\end{tabular}

TABLE (3) The relative remnant index of all subgroups as related to the control group mean record:

\begin{tabular}{|c|c|c|c|c|c|c|c|}
\hline Specimen & Control_I & I_A & $* \mathbf{R I}$ & I_B & $* \mathbf{R I}$ & I_C & $* \mathbf{R I}$ \\
\hline 1 & \multirow{6}{*}{48.7} & 36.9 & 75.8 & 26.88 & 55.2 & 0.98 & 2.01 \\
\hline 2 & & 17.7 & 36.3 & 24.11 & 49.5 & 1.22 & 2.5 \\
\hline 3 & & 30.04 & 61.7 & 29.33 & 60.2 & 1.05 & 2.2 \\
\hline 4 & & 26.89 & 55.2 & 24 & 49.3 & 0.91 & 1.9 \\
\hline 5 & & 24.97 & 51.3 & 16.83 & 34.6 & 0.54 & 1.1 \\
\hline Mean & & 27.3 & 56.1 & 24.23 & 49.8 & 0.94 & 1.9 \\
\hline Specimen & Control_2 & II_A & $* \mathbf{R I}$ & II_B & $* \mathbf{R I}$ & II_C & $* \mathbf{R I}$ \\
\hline 1 & \multirow{6}{*}{76.6} & 48.2 & 62.9 & 62.5 & 81.6 & 30.5 & 39.82 \\
\hline 2 & & 50.98 & 66.6 & 16.1 & 21.01 & 30 & 39.16 \\
\hline 3 & & 45.3 & 59.1 & 40.08 & 52.3 & 29.6 & 38.64 \\
\hline 4 & & 49 & 63.9 & 39.9 & 52.1 & 30.9 & 40.46 \\
\hline 5 & & 47.32 & 61.8 & 37.92 & 49.5 & 31.1 & 40.6 \\
\hline Mean & & 48.16 & 62.9 & 39.3 & 40.9 & 30.44 & 39.74 \\
\hline
\end{tabular}

*RI $($ Remnant Index $)=[($ subgroup reading/Control reading $) x 100]$ 


\section{DISCUSSION}

Scanning electron microscopy (SEM) imaging and digital image analysis are great tools that provide both descriptive and quantitative analysis of surface topography. Beside those researches that used SEM imaging and digital image analysis ${ }^{[1]}$, many other tools have been used for the same purpose, e.g., the cone-beam computed tomography ${ }^{[12]}$, the dental microscope ${ }^{[13]}$, and the stereomicroscope attached to a digital camera ${ }^{[14]}$.

The question of "How many files should be used for apical enlargement of a canal that has been des-obturated for the sake of retreatment?" is an important question that needs an answer. However, the answer should be augmented by a scientific research based on a study design that reveals the phase at which acceptable canal wall cleanliness is obtained. Cleanliness of canal walls is a multiplefactors-dependent outcome. It depends on the type of canal filling material and the used sealer, the type of solvent, duration of exposure of canal filling to the solvent, effective flushing and adsorption of the resultant emulsion, and amount of mechanical enlargement and shaving of canal walls. Here comes the need to conduct our study, aiming to reveal the influence of some of these factors including type of the sealer and size of apical enlargement.

Within the parameters of the present study, increasing the size of apical preparation (from size \#30-0.04 to size \#40-0.04) - within limits - resulted in better canal wall cleanliness. This observation corroborates results obtained by several studies ${ }^{[15-19]}$.

Bioceramic materials are well-known for their biocompatibility that prevents rejection by the surrounding tissues ${ }^{[5]}$ and chemical bonding to tooth structure. Calcium phosphate component in bioceramics enhances their setting properties and results in a chemical composition with a crystalline structure similar to tooth and bone apatite materials ${ }^{[20]}$. As a result, sealer-to-root dentin bonding is greatly improved.

In gutta percha/AH-Plus desobturated canals, apical enlargement to file size \#30-0.04 and \#350.04 (one or two sizes larger than the master apical file) had similar impact over the amount of remnants left in the apical third. On the other hand, in gutta percha/TotalFill desobturated canals, apical enlargement to file size \#35-0.04 or \#40-0.04 (two or three sizes larger than the master apical file) had similar impact over the amount of remnants left in the area. Minimal apical enlargement would preserve the dentin thickness and root integrity ${ }^{[21]}$. Hence, apical enlargement to one size (in case of AH-Plus sealer) or two sizes (in case of TotalFill sealer) larger than the master apical file is quite enough in cleaning the remnants of the sealer after desobturation. The difficulty in removing TotalFill from the root canal once set - and consequently in obtaining a sealer-free clean dentin surface - in case of retreatment or post-space preparation, is considered as a major drawback of the bioceramic sealers ${ }^{[22,23]}$.

\section{CONCLUSIONS}

Increasing the size of the apical preparation within limits - improves the cleanliness of canal walls at the apical third area. After desobturation and apical enlargement, TotalFill sealer leaves more remnants on the dentin surface of the apical third when compared to AH-Plus sealer. Within the parameters of this study, and whenever canal size and apical thickness and shape of the root allow, it's better to enlarge the apical third of the canal two or three sizes larger than the master apical file (in case of desobturation of bioceramic-sealer-containing canal filling) to ensure better cleanliness of the area.

\section{Conflict of interests' declaration}

I declare that I don't have any conflict of interests. 


\section{REFERENCES}

1. Imura N, Zuolo ML, Ferreira MO, Novo NF. Effectiveness of the Canal Finder and hand instrumentation in removal of gutta-percha root fillings during root canal retreatment. International endodontic journal. 1996 Nov 1;29(6):382-6.

2. Obeid MF, Nagy MM. Retreatability of different endodontic sealers using chemical solvents. Tanta Dental Journal. 2015 Dec 31;12(4):286-91.

3. Hench LL. Bioceramics: from concept to clinic. Journal of the american ceramic society. 1991 Jul 1;74(7):1487-510.

4. Best SM, Porter AE, Thian ES, Huang J. Bioceramics: past, present and for the future. Journal of the European Ceramic Society. 2008 Dec 31;28(7):1319-27.

5. Koch K, Brave D. A new day has been dawned: The increased use of bio-ceramics in endodontics. Endodontics. 2009;11(4):39-43.

6. Saikia KC, Bhattacharya TD, Bhuyan SK, Talukdar DJ, Saikia SP, Jitesh P. Calcium phosphate ceramics as bone graft substitutes in filling bone tumor defects. Indian journal of orthopaedics. 2008 Apr; 42(2):169.

7. PRESS RELEASE FKG Dentaire SA, La Chaux de Fonds, Switzerland, 7 October 2013, accessed 4 September 2017, [http://www.fkg.ch/sites/default/files/fkg_totalfill_press_ release_en_0.pdf]

8. Nagas E, Uyanik MO, Eymirli A, Cehreli ZC, Vallittu PK, Lassila LV, Durmaz V. Dentin moisture conditions affect the adhesion of root canal sealers. Journal of Endodontics. 2012 Feb 29;38(2):240-4.

9. Ghoneim AG, Lutfy RA, Sabet NE, Fayyad DM. Resistance to fracture of roots obturated with novel canal-filling systems. Journal of endodontics. 2011 Nov 30;37(11):1590-2.

10. Ng YL, Mann V, Gulabivala K. A prospective study of the factors affecting outcomes of nonsurgical root canal treatment: part 1: periapical health. International endodontic journal. 2011 Jul 1;44(7):583-609.

11. Plotino G, Grande NM, Tocci L, Testarelli L, Gambarini $\mathrm{G}$. Influence of different apical preparations on root canal cleanliness in human molars: a SEM study. Journal of oral \& maxillofacial research. 2014 Apr;5(2).

12. Seixas FH, Estrela C, Bueno MR, Sousa-Neto MD, Pecora JD. Determination of root canal cleanliness by different irrigation methods and morphometric analysis of apical third. J Contemp Dent Pract. 2015 Jun 1;16:442-50.

13. Wilkonski W, Karas B, Jamroz-Wilkonska L, Krupinski J, Opila J. The comparison of root canal cleanliness after the application of three systems of machine instruments - In
Vitro study. Oral Health 2016;(5), accessed 4 September 2017, [https://www.oralhealthgroup.com/features/comparison-root-canal-cleanliness application-three-systemsmachine-instruments-vitro-study/].

14. Karamifar K, Mehrasa N, Pardis P, Saghiri MA. Cleanliness of Canal Walls following Gutta-Percha Removal with Hand Files, RaCe and RaCe plus XP-Endo Finisher Instruments: A Photographic in Vitro Analysis. Iranian endodontic journal. 2017;12(2):242.

15. Ørstavik D, Kerekes K, Molven O. Effects of extensive apical reaming and calcium hydroxide dressing on bacterial infection during treatment of apical periodontitis: a pilot study. International Endodontic Journal. 1991 Jan $1 ; 24(1): 1-7$.

16. Siqueira JF, Lima KC, Magalhães FA, Lopes HP, de Uzeda $\mathrm{M}$. Mechanical reduction of the bacterial population in the root canal by three instrumentation techniques. Journal of Endodontics. 1999 May 1;25(5):332-5.

17. Wu MK, Wesselink PR. Efficacy of three techniques in cleaning the apical portion of curved root canals. Oral Surgery, Oral Medicine, Oral Pathology, Oral Radiology, and Endodontology. 1995 Apr 30;79(4):492-6.

18. Shuping GB, Ørstavik D, Sigurdsson A, Trope M. Reduction of intracanal bacteria using nickel-titanium rotary instrumentation and various medications. Journal of endodontics. 2000 Dec 31;26(12):751-5.

19. Albrecht LJ, Baumgartner JC, Marshall JG. Evaluation of apical debris removal using various sizes and tapers of ProFile GT files. Journal of Endodontics. 2004 Jun 30;30(6):425-8.

20. Ginebra MP, Fernandez E, De Maeyer EA, Verbeeck RM, Boltong MG, Ginebra J, Driessens FC, Planell JA. Setting reaction and hardening of an apatitic calcium phosphate cement. Journal of dental research. 1997 Apr;76(4): 905-12.

21. ElAyouti A, Dima E, Judenhofer MS, Löst C, Pichler BJ. Increased apical enlargement contributes to excessive dentin removal in curved root canals: a stepwise microcomputed tomography study. Journal of endodontics. 2011 Nov 30;37(11):1580-4

22. Cherng AM, Chow LC, Takagi S. In vitro evaluation of a calcium phosphate cement root canal filler/sealer. Journal of endodontics. 2001 Oct 31;27(10):613-5.

23. Oltra E, Cox TC, LaCourse MR, Johnson JD, Paranjpe A. Retreatability of two endodontic sealers, EndoSequence BC Sealer and AH Plus: a micro-computed tomographic comparison. Restorative dentistry \& endodontics. 2017 Feb 1;42(1):19-26. 